\title{
PENGENALAN SERTA PERKEMBANGAN E-LEARNING DALAM SEKTOR PENDIDIKAN DAN SEKTOR KORPORAT
}

\author{
Dini Purwaningsih \\ Prodi Sistem Informasi \\ STMIK Bahrul 'Ulum Jombang
}

\begin{abstract}
ABSTRAKSI
Dalam perkembangan kehidupan manusia saat ini, sektor teknologi informasi dan telekomunikasi merupakan sektor yang cukup dominan. Sektor ini mempunyai andil besar dalam meningkatkan kualitas sector-sektor lainnya misalnya sector perekonomian, pendidikan, pemerintahan dan lainnya. Yang marak disoroti saat ini adalah peranan sector teknologi informasi dan telekomunikasi terhadap kemajuan sector pendidikan karena sector pendidikan adalah salah satu sector yang mendapat prioritas utama dari pemerintah untuk selalu dikembangkan menjadi lebih baik. Globalisasi telah memicu pergeseranpergeseran dalam sektor pendidikan dari yang menggunakan metode konvensional ke arah pendidikan yang lebih terbuka, lebih fleksibel, dua arah, beragam, multidisipliner, serta terkait pada produktivitas kerja "saat itu juga" dan kompetitif.
\end{abstract}

Metode yang sekarang marak dikembangkan dalam sector pendidikan adalah E-Learning.

\section{A. PENDAHULUAN}

Dalam perkembangan kehidupan manusia saat ini, sektor teknologi informasi dan telekomunikasi merupakan sektor yang cukup dominan. Sektor ini mempunyai andil besar dalam meningkatkan kualitas sector-sektor lainnya misalnya sector perekonomian, pendidikan, pemerintahan dan lainnya. Yang marak disoroti saat ini adalah peranan sector teknologi informasi dan telekomunikasi terhadap kemajuan sector pendidikan karena sector pendidikan adalah salah satu sector yang mendapat prioritas utama dari pemerintah untuk selalu dikembangkan menjadi lebih baik. Globalisasi telah memicu pergeseranpergeseran dalam sektor pendidikan dari yang menggunakan metode konvensional ke arah pendidikan yang lebih terbuka, lebih fleksibel, dua arah, beragam, multidisipliner, serta terkait pada produktivitas kerja "saat itu juga" dan kompetitif.

Metode yang sekarang marak dikembangkan dalam sector pendidikan adalah E-Learning.

Ada beberapa ahli telah berpendapat tentang kemajuan sector pendidikan akibat peran dari sector teknologi informasi dan telekomunikasi.

Misalnya beberapa pendapat dari:

* Ivan Illich, tahun 70-an mengagas tentang "Pendidikan tanpa Sekolah (Deschooling Socieiy)" yang secara ekstrim guru tidak lagi diperlukan.

* Bishop G., tahun 1989 meramalkan bahwa pendidikan mendatang akan bersifat luwes (flexible), terbuka, dan dapat diakses oleh siapapun yang memerlukan tanpa batasan usia maupun pengalaman pendidikan sebelumnya.

* Mason R., tahun 1994 berpendapat bahwa pendidikan mendatang akan lebih ditentukan oleh jaringan informasi yang memungkinkan terjadinya interaksi dan kolaborasi.. 
* Tony Bates, tahun 1995 menyatakan bahwa teknologi dapat meningkatkan kualitas dan jangkauan bila digunakan secara bijak untuk pendidikan dan latihan, dan mempunyai arti yang sangat penting untuk kesejahteraan ekonomi.

* Alisjahbana I., tahun 1966 mengemukakan bahwa pendekatan pendidikan dan pelatihan akan bersifat "Saat itu juga (Just on Time)", teknik pengajaran akan bersifat dua arah, kolaboratif, dan interdisipliner.

* Romiszowski \& Mason (1996) memprediksi penggunaan "Computer-based Multimedia Communication (CMC)" yang bersifat sinkron dan asinkron.

\section{B. PENGERTIAN E-LEARNING}

Jaya Kumar C. Koran (2002), mendefinisikan e-learning sebagai sembarang pengajaran dan pembelajaran yang menggunakan rangkaian elektronik (LAN, WAN, atau internet) untuk menyampaikan isi pembelajaran, interaksi, atau bimbingan.

Dong (dalam Kamarga, 2002), mendefinisikan e-learning sebagai kegiatan belajar asynchronous melalui perangkat elektronik komputer yang memperoleh bahan belajar yang sesuai dengan kebutuhannya.

(Soekartawi, Haryono dan Librero, 2002), mendefinisikan e-learning sebagai berikut : eLearning is a generic term for all technologically supported learning using an array of teaching and learning tools as phone bridging, audio and videotapes, teleconferencing, satellite transmissions, and the more recognized web-based training or computer aided

\section{instruction also commonly referred to as online courses.}

Rosenberg (2001) mendefinisikan e-learning merujuk pada penggunaan teknologi internet untuk mengirimkan serangkaian solusi yang dapat meningkatkan pengetahuan dan keterampilan.

Onno W. Purbo (2002), mendefinisikan e-learning sebagai istilah untuk segala teknologi yang digunakan untuk mendukung usaha-usaha pengajaran lewat teknologi elektronik internet.

Dari bebrapa pendapat tersebut dapat ditarik kesimpulan bahwa e-learning adalah pembelajaran jarak jauh (distance learning) yang memanfaatkan teknologi komputer, jaringan komputer dan/atau Internet.

E-learning memungkinkan siswa untuk belajar melalui komputer di tempat mereka masing-masing tanpa harus secara fisik pergi mengikuti pelajaran/perkuliahan di kelas. Materi e-learning tidak harus didistribusikan secara on-line baik melalui jaringan lokal maupun internet, distribusi secara off-line menggunakan media CD/DVD pun termasuk pola e-learning. Dalam hal ini aplikasi dan materi belajar dikembangkan sesuai kebutuhan dan didistribusikan melalui media CD/DVD, selanjutnya siswa dapat memanfatkan CD/DVD tersebut dan belajar di tempat di mana dia berada.

Ada satu hal yang perlu dipahami dalam E-Learning yaitu tentang Pembelajaran jarak jauh. Pembelajaran jarak jauh adalah pembelajaran yang siswanya terpisah dari pendidik dan pembelajarannya menggunakan berbagai sumber belajar melalui teknologi komunikasi, informasi, dan media lain. Pada umumnya perangkat dilengkapi perangkat multimedia, dengan cd drive dan koneksi Internet ataupun Intranet lokal. Dengan memiliki komputer 
yang terkoneksi dengan intranet ataupun Internet, pembelajar dapat berpartisipasi dalam elearning. Jumlah pembelajar yang bisa ikut berpartisipasi tidak dibatasi dengan kapasitas kelas. Pembelajaran jarak jauh ini lebih menekankan kepada belajar mandiri yaitu kegiatan belajar yang dilakukan oleh siswa secara mandiri baik secara perorangan maupun kelompok dengan memanfaatkan berbagai sumber belajar. Sumber belajar disini diartikan sebagai sarana, narasumber, teknik, lingkungan, bahan ajar, dan media yang dimanfaatkan oleh siswa dalam proses pembelajaran jarak jauh. Dimana bahan ajar itu sendiri adalah kemasan materi pembelajaran yang dikembangkan sebagai bahan yang dapat dipelajari secara mandiri dan dimanfaatkan dalam proses pembelajaran jarak jauh. Pembelajaran jarak jauh dapat diselenggarakan dengan cakupan pendidikan berbasis mata pelajaran (terbatas untuk satu atau beberapa mata pelajaran), program studi/pendidikan, atau satuan pendidikan. Pembelajaran jarak jauh dapat diselenggarakan dalam modus pengorganisasian tunggal (single mode), ganda (dual mode), atau konsorsium. Pengorganisasian Pembelajaran jarak jauh modus tunggal berbentuk satuan pendidikan yang menyelenggarakan program pendidikan hanya secara jarak jauh. Pengorganisasian modus ganda berbentuk satuan pendidikan yang menyelenggarakan program pendidikan baik secara tatap muka maupun jarak jauh. Pengorganisasian modus konsorsium berbentuk jejaring penyelenggaraan pendidikan jarak jauh secara kolaboratif atau kerja sama secara lintas satuan pendidikan dengan lingkup wilayah nasional dan/atau internasional.

Selain memanfaatkan perangkat computer, E-Learning juga dikelola oleh tim yang terdiri dari para ahli di bidang masing-masing, yaitu:

1) Subject Matter Expert (SME) bertugas sebagai nara sumber dari pelatihan yang disampaikan.

2) Instructional Designer (ID) bertugas mendesain materi dari SME menjadi materi elearning dengan memasukkan unsur metode pengajaran agar materi menjadi lebih interaktif, lebih mudah dan lebih menarik untuk dipelajari.

3) Graphic Designer (GD) bertugas mengubah materi text menjadi bentuk grafis dengan gambar, warna, dan layout yang enak dipandang, efektif dan menarik untuk dipelajari.

4) Ahli bidang Learning Management System (LMS) bertugas mengelola sistem di website yang mengatur lalu lintas interaksi antara instruktur dengan siswa, antarsiswa dengan siswa lainnya.

Sehingga siswa bisa melihat modul-modul yang ditawarkan, bisa mengambil tugas-tugas dan test-test yang harus dikerjakan, serta melihat jadwal diskusi secara maya dengan instruktur. Melalui LMS ini, siswa juga bisa melihat nilai tugas dan test serta peringkatnya berdasarkan nilai (tugas ataupun test) yang diperoleh. 


\section{PENGEMBANGAN MODEL}

Pendapat Haughey (1998) tentang pengembangan e-learning. Menurutnya ada tiga kemungkinan dalam pengembangan sistem pembelajaran berbasis internet, yaitu web course, web centric course, dan web enhanced course.

1. Web course adalah penggunaan internet untuk keperluan pendidikan, yang mana siswa dan pengajar sepenuhnya terpisah dan tidak diperlukan adanya tatap muka. Seluruh bahan ajar, diskusi, konsultasi, penugasan, latihan, ujian, dan kegiatan pembelajaran lainnya sepenuhnya disampaikan melalui internet. Dengan kata lain model ini menggunakan sistem jarak jauh.

2. Web centric course adalah penggunaan internet yang memadukan antara belajar jarak jauh dan tatap muka (konvensional). Sebagian materi disampikan melalui internet, dan sebagian lagi melalui tatap muka. Fungsinya saling melengkapi.

Dalam model ini pengajar bisa memberikan petunjuk pada siswa untuk mempelajari materi pelajaran melalui web yang telah dibuatnya. Siswa juga diberikan arahan

untuk mencari sumber lain dari situs-situs yang relevan. Dalam tatap muka, siswa dan pengajar lebih banyak diskusi tentang temuan materi yang telah dipelajari melalui internet tersebut.

3. Web enhanced course adalah pemanfaatan internet untuk menunjang peningkatan kualitas pembelajaran yang dilakukan di kelas. Fungsi internet adalah untuk memberikan pengayaan dan komunikasi antara siswa dengan pengajar, sesama siswa, anggota kelompok, atau siswa dengan nara sumber lain.

Oleh karena itu peran pengajar dalam hal ini dituntut untuk menguasai teknik mencari informasi di internet, membimbing siswa mencari dan menemukan situs-situs yang relevan dengan bahan pembelajaran, menyajikan materi melalui web yang menarik dan diminati, melayani bimbingan dan komunikasi melalui internet, dan kecakapan lain yang diperlukan.

\section{SYARAT SUKSESNYA E-LEARNING}

Suksesnya program E-Learning sangat tergantung dari penilaian apakah:

1. E-Learning itu sudah menjadikan suatu kebutuhan;

2. Tersedianya infrastruktur pendukung seperti telepon dan listrik;

3. Tersedianya fasilitas jaringan internet (Internet Infrastructure) dan koneksi internet (Internet Connections);

4. Software pembelajaran (management course tools);

5. Kemampuan dan ketrampilan orang yang mengoperasikannya;

6. Kebijakan yang mendukung pelaksanaan program e-Learning tersebut. 


\section{E. MANFAAT E-LEARNING}

Terdapat beberapa manfaat yang dapat diperoleh dari implementasi e-learning yaitu :

\section{Fleksibel}

E-learning memberikan fleksibilitas bagi siswa dalam pemilihan waktu dan tempat untuk mengakses pelajaran. Disini siswa tidak perlu mengadakan perjalanan menuju tempat pelajaran disampaikan, e-learning bisa dilakukan dari mana saja baik yang memiliki akses ke Internet ataupun tidak. Bagi yang tidak memiliki koneksi internet, e-learning didistribusikan melalui movable media spe CD/DVD. Pada perkembangan terakhir, dengan semakin canggihnya teknologi maka siswa saat ini dapat pula memanfaatkan mobile technology seperti notebook, pda, atau telepon selular untuk mengakses e-learning. Fleksibiltas di dukung juga karena saat ini berbagai tempat sudah menyediakan sambungan internet / hot spot gratis menggunakan wi-fi atau wimax.

\section{Belajar Mandiri}

E-learning memberikan kesempatan kepada siswa agar mampu belajar secara mandiri sehingga keberhasilan belajar ditentukan oleh kemampuan siswa itu sendiri. Siswa bebas menentukan kapan akan mulai, kapan akan menyelesaikan, dan bagian mana dalam satu modul yang ingin dipelajarinya terlebih dulu. Seandainya, setelah diulang masih ada hal yang belum ia pahami, siswa bisa menghubungi instruktur, nara sumber melalui email, chat atau ikut dialog interaktif pada waktu-waktu tertentu. Bisa juga membaca hasil diskusi di message board yang tersedia di LMS (Learning Management System).

\section{Efisiensi Biaya}

E-Learning memberikan banyak sekali efisiensi biaya, yaitu :

a. Bagi penyelenggara, dalam hal ini universitas misalnya dapat menghemat biaya administrasi pengelolaan (biaya gaji dan tunjangan selama pelatihan, biaya dosen pengajar dan tenaga administrasi pengelola pelatihan, makanan selama pelatihan),

penyediaan sarana dan fasilitas fisik untuk belajar (misalnya: penyewaan ataupun penyediaan ruang kelas, kursi, papan tulis, LCD player, OHP).

b. Bagi siswa, dapat menghemat biaya transportasi dan akomodasi.

Salah satu contoh nyata adalah jika suatu sektor bisnis/korporat, apabila sebuah perusahaan skala nasional dengan cabang di bebagai propinsi akan memberikan pelatihan bagi karyawannya dari seluruh cabang di Indonesia, tentu banyak sekali biaya transportasi dan akomodasi yang harus dikeluarkan untuk melaksanakan pelatihan tersebut. Sehingga dengan e-learning, dapat mengefisiensikan biaya tersebut karena materi pelatihan dapat didistribusikan baik secara on-line maupun off-line ke seluruh cabang yang ada, tanpa mengharuskan karyawan meninggalkan pekerjaannya untuk sementara waktu selama mengikuti pelatihan karena karyawan dapat mempelajari materi pelatihan di tempat kerjanya. 


\section{F. PENGIMPLEMENTASIAN E-LEARNING}

E-learning adalah suatu alternatif baru pola pembelajaran, dimana E-learning menggabungkan aspek pengajaran dan pemanfaatan teknologi informasi. Secara garis besar, saat ini e-learning telah diimplementasikan di 2 sektor yaitu :

\section{Sektor korporat atau perusahaan}

Di sektor korporat, e-learning dibutuhkan oleh perusahaan-perusahaan skala menengahbesar untuk memberikan pelatihan atau menditribusikan materi-materi training bagi karyawannya dengan cepat dan efisien karena karyawan dapat secara bebas mengakses dan mempelajari pada waktu yang mereka atur sendiri menyesuaikan jadwal kerjanya.. Dengan pola e-learning, material training seperti pengenalan produk baru (product knowledge), strategi pemasaran, kebijakan harga jual, dll dapat disiapkan dan didistribusikan secara lengkap dan terstruktur.

\section{Sektor pendidikan}

Saat ini memang e-learning sebagian besar masih diimplementasikan di intitusi pendidikan tinggi, perguruan tinggi atau universitas-universitas hal ini karena kebutuhan e-learning di sektor ini tak lepas dari faktor globalisasi dan efisiensi.

Globalisasi pendidikan mendorong terjalinnya kerjasama pendidikan antar institusi pendidikan baik yang ada di dalam negeri maupun di luar negeri. Kerjasama bisa berupa pengembangan materi, pembelajaran jarak jauh, pertukaran pengajar, penyediaan referensi / literatur, penyelenggaraan ujian, sertifikasi, dll.

Efisiensi juga menjadi faktor pendorong diimplementasikannya e-learning di beberapa institusi pendidikan tinggi di Indonesia, yang meliputi efisiensi baik bagi penyelenggara dalam hal ini pihak universitas maupun efisiensi bagi para mahasiswanya.

Dengan e-learning, perkuliahan dapat didistrubusikan secara remote ke masing-masing fakultas/jurusan sehingga pengelolaan akan menjadi lebih mudah dan efisien.

\section{G. PERAN INDUSTRI TI DALAM PERKEMBANGAN E-LEARNING}

E-learning mampu berkembang dengan cepat karena dukungan penuh teknologi informasi. E-learning dikembangkan dari perpaduan aspek pembelajaran dan aspek teknologi. Dari sisi teknologi, keberhasilan e-learning mencakup perpaduan aspek teknologi Software, Hardware \& Networking/communication

Secara garis besar, kontribusi atau peran dari perusahaan-perusahaan atau vendor TI terhadap perkembangan implementasi e-learning dapat dikategorikan menjadi dua, yaitu sebagai :

\section{Technology Provider}

Technology provider memfokuskan pada pengembangan aplikasi e-learning dan platform berbasis web. Technology provider mengembangkan software-software yang dibutuhkan untuk penyusunan materi pembelajaran hingga pengembangan aplikasi pengelola sistem elearning. Technology provider di bidang e-learning memiliki spesialisasi yang berbeda, antara lain :

a. Pengembang LMS -Learning Management System 
Learning Management System (LMS) berfungsi menyimpan, mengelola dan mendistribusikan berbagai materi pelatihan, ujian/test yang telah disiapkan. LMS dilengkapi dengan katalog on-line sehingga siswa dapat mengakses, memilih dan menjalankan berbagai materi pelatihan yang ada.

b. Pengembang Software E-Learning Authoring

Pengembang Software E-Learning Authoring mengembangkan Software authoring yaitu software yang dibutuhkan untuk mendesain dan menyusun materi pelatihan interaktif, test, presentasi, simulasi, web content dengan menggabungkan berbagai content multimedia.

c. Pengembang Hardware \& Networking

Beberapa pengembang lainnya lebih memfokuskan pada dukungan di aspek perangkat keras dan insfrastruktur pendukung dalam implementasi e-learning. Misalnya perkembangan-perkembangan baru dalam teknologi perangkat jaringan, karena hal ini sangat mendorong perkembangan e-learning.

\section{H. PENUTUP}

Dari berbagai implementasi E-Learning pada beberapa sector kehidupan terutama pendidikan dan korporat, metode pembelajaran ini adalah metode yang sangat menarik, atraktif, efisien, fleksibel serta melatih kemandirian siswa/pembelajar pengguna ELearning. E-learning juga mampu meningkatkan peran guru/nara sumber dari yang semula hanya menguasai teknik pembelajaran konvensional, kini mereka mampu mengetahui teknik pembelajaran yang menggunakan ICT.

Sehingga di masa mendatang, perkembangan e-learning di Indonesia diyakini akan semakin pesat. E-learning akan semakin banyak diimplementasikan di universitasuniversitas di tanah air. Di sektor korporat, akan semakin banyak jumlah perusahaanperusahaan besar maupun menengah yang akan mulai menerapkan kebijakan distancelearning atau pembelajaran jarak jauh untuk pelatihan bagi para karyawannya, hal ini untuk meminimalkan biaya pelatihan yang tinggi.

Hal yang terpenting dalam pengembangan E-learning adalah pengembangan teknologi pendukung yang harus selalu up-to-date guna didapatkan system metode pembelajaran elearningn yang semakin mudah, efektif serta menjangkau semua lapisan masyarakat.

Terkait dengan tuntutan tersebut maka akan mendorong pengembang-pengembang teknologi pendukung e-learning semakin berkompetisi menghasilkan produk-produk baru. Sehingga produk-produk software pendukung e-learning baik produk pengembangan content maupun software pengelola e-learning (LMS) akan semakin berkompetisi. 


\section{DAFTAR PUSTAKA}

- Antonius Aditya Hartanto dan Onno W. Purbo, E-Learning berbasis PHP dan MySQL, Penerbit Elex Media Komputindo, Jakarta, 2002.

- Romi Satria Wahono, Strategi Baru Pengelolaan Situs eLearning Gratis, http://www.ilmukomputer.com, 2003

- http://www.elearning-reviews.org

- Asep Herman Suyanto, MENGENAL E-LEARNING, http://www.asep-hs.web.ugm.ac.id

- Jaya Kumar C. Koran, Aplikasi ‘E-Learning’ Dalam Pengajaran Dan Pembelajaran Di Sekolah-Sekolah Malaysia: Cadangan Perlaksanaan Pada Senario Masa Kini,

Pasukan Projek Rintis Sekolah Bestari Bahagian Teknologi Pendidikan,

Kementerian Pendidikan Malaysia.

- Asep Saepudin, Penerapan Teknologi Informasi Dalam Pendidikan Masyarakat, Jurnal Teknodik, Edisi No.12/VII/Oktober/2003.

- Soekartawi (1995), Monitoring dan Evaluasi Proyek Pendidikan, PT Rajawali Press, Jakarta. 